\title{
Thirteen years of integrated precipitable water derived by GPS at Mario Zucchelli Station, Antarctica
}

\author{
Pierguido Sarti ${ }^{1,}{ }^{\star}$, Monia Negusini ${ }^{1}$, Claudio Tomasi ${ }^{2}$, Boyan H. Petkov ${ }^{2,3}$, Alessandro Capra ${ }^{4}$ \\ ${ }^{1}$ Istituto di Radioastronomia (IRA), Istituto Nazionale di Astrofisica (INAF), Bologna, Italy \\ ${ }^{2}$ Istituto di Scienze dell'Atmosfera e del Clima (ISAC), Consiglio Nazionale delle Ricerche (CNR), Bologna, Italy \\ ${ }^{3}$ International Centre for Theoretical Physics (ICTP), Trieste, Italy \\ ${ }^{4}$ Università degli Studi di Modena e Reggio Emilia, Dipartimento di Ingegneria "Enzo Ferrari" (DIEF), Modena, Italy
}

Article history

Received October 12, 2012; accepted March 27, 2013.

Subject classification:

Composition and structure, Instruments and techniques, Measurements and monitoring, Satellite geodesy, Data processing.

\section{ABSTRACT}

Since 1998, the Italian Antarctic Programme has been funding space geodetic activities based on the use of episodic and permanent global positioning system (GPS) observations. As well as their exploitation in geodynamics, these data can be used to sense the atmosphere and to retrieve and monitor its water vapor content and variations. The surface pressure $\mathrm{p}$ and temperature $\mathrm{T}_{\mathrm{s}}$ at the GPS tracking sites are necessary to compute the zenith hydrostatic delay (ZHD), and consequently, the precipitable water. At sites where no surface information is recorded, the $\mathrm{p}$ and $\mathrm{T}_{\mathrm{s}}$ values can be retrieved from, e.g., global numerical weather prediction models. Alternatively, the site-specific ZHD values can be computed by interpolation of the ZHD values provided in a grid model $\left(2.5^{\circ} \times 2.0^{\circ}\right)$. We have processed the data series of the permanent GPS site TNB1 (Mario Zucchelli Station, Antarctica) from 1998 to 2010, with the purpose of comparing the use of grid ZHD values as an alternative to the use of real surface records. With these approaches, we estimate almost $7 \times 10^{4}$ hourly values of precipitable water over 13 years, and we find discrepancies that vary between $1.8( \pm 0.2) \mathrm{mm}$ in summer and 3.3 $( \pm 0.5) \mathrm{mm}$ in winter. In addition, the discrepancies of the two solutions show a clear seasonal dependency. Radiosounding measurements were used to derive an independent series of precipitable water. These agree better with the GPS precipitable water derived from real surface data. However, the GPS precipitable water time series is dry biased, as it is ca. $77 \%$ of the total moisture measured by the radiosoundings. Both the GPS and radiosounding observations are processed through the most up-todate strategies, to reduce known systematic errors.

\section{Introduction}

The Mario Zucchelli Station (MZS; 74 41' 55.70" S, $\left.164^{\circ} 06^{\prime} 10.59^{\prime \prime} \mathrm{E}\right)$, which was formerly known as Baia Terra Nova, was established in 1986 at Terra Nova Bay, Northern Victoria Land, Antarctica, during the second Italian scientific expedition. The geodetic global positioning system (GPS) station TNB1 was permanently constructed in November 1998, on a granite hill in close vicinity to the MZS [Capra et al. 2003]. It has a Dorne Margolin ASH700936 antenna with a snow radome that is positioned on a concrete pillar that is built on a massive, stable granite outcrop (Figure 1). Over the same outcrop, next to the geodetic pillar, there is a small shelter that hosts the Ashtech-ZXII receiver, the $56-\mathrm{kb}$ modem used for data transmission, the power supply equipment, the back-up batteries, a small heater, and the receiver of a second ancillary GPS station (TNB2) installed in 2008, some $14 \mathrm{~m}$ from TNB1.

Since 1998, TNB1 has been continuously acquiring GPS observations with a 15 -s rate and a cut-off that varies between $5^{\circ}$ and $10^{\circ}$ elevation. It has been used as the reference station for all of the GPS-based geodetic applications carried out around MZS and in the wider Northern Victoria Land area. A few serious power supply disruptions have occurred, due to electrical instabilities in the MZS power circuits. Consequently, there are some breaks in the observation time series: from May 1999, a few months after its installation, to November 1999; and from October 2007 to December 2009, when only a few weeks of data are available.

The long time series of TNB1 data has mainly been processed to monitor crustal deformation. Since December 1999, this time series has been combined with the episodic GPS campaigns carried out on the Victoria Land Network Deformation (VLNDEF) network sites [Mancini et al. 2004], to investigate crustal kinematics and geodynamics in Northern Victoria Land [see e.g., Capra et al. 2002, 2007, 2008, Negusini et al. 2005, Dubbini et al. 2010].

As well as these classical applications of GPS, the long time series of TNB1 can also be used to investigate 


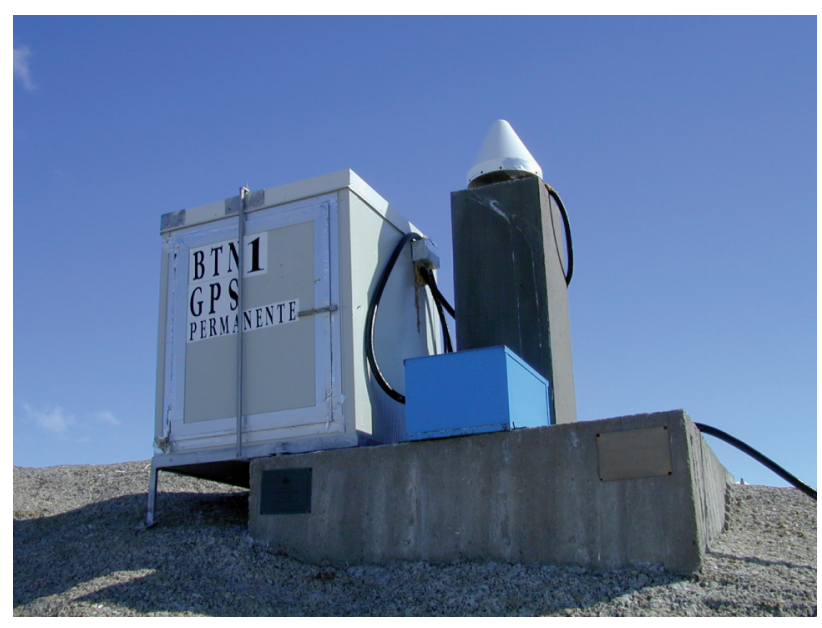

Figure 1. The TNB1 permanent GPS station, the antenna and its cone radome, and the shelter that contains the Ashetch-ZXII receiver and the ancillary equipment.

the amount and variation of atmospheric water vapor. Indeed, the use of GPS for precipitable water retrieval and meteorological applications was highlighted as long ago as 20 years [Bevis et al. 1992]. In propagating from the satellites to the tracking station, the GPS signals interact with the atmospheric media. The propagation through the lower, unionized part (stratosphere, troposphere) bends and delays the electromagnetic waves, which introduces an error into the satellite slant range. The total delay (TD) depends on the atmospheric pressure and temperature, and water vapor concentration [Hopfield 1978]. This atmospheric effect has been transformed from a nuisance in the precision of geodetic investigations into an interesting and promising scientific/ meteorological application of GPS.

There has been increasing interest in the use of GPS-derived atmospheric parameters in global climate and weather models [see e.g. Bennitt and Jupp 2012, Vonder Haar et al. 2012], although these can be effectively integrated only if homogeneous and unbiased precipitable water estimates are provided. The role of the Antarctic water vapor in predictions of global climate models is very important [see e.g. Monaghan et al. 2008]. In such remote, hardly accessible and desert areas, permanent GPS observations can fill the spatial observation gaps, to add important information to our understanding of the radiative forcing of water vapor and to predict future climate variations.

Several studies have compared the GPS performances for precipitable water retrieval with other satellite, ground-based and aerial methods, with overall satisfying agreement generally obtained in terms of relative variations, although not always in terms of absolute values [see e.g. Wang et al. 2007]. The bias is usually identified as systematic errors that are not handled properly in the data analysis of these techniques.

On the space geodetic side, the reduction in the systematic errors obtained with homogeneous data reprocessing has been discussed in several studies [see e.g. Steigenberger et al. 2006, 2009b, Tesmer et al. 2009, Rothacher et al. 2011]. Some investigations have specifically focused on the reprocessing of the GPS data to study the TD signal [Steigenberger et al. 2007] and to consistently estimate the precipitable water [Vey et al. 2009]. However, in addition to homogeneous reprocessing of the data, it is crucial to parameterize the space geodetic observable with accurate models, as clearly pointed out by Thomas et al. [2011] in a recent study carried out over the Antarctic region.

In our investigation, we focus on the homogeneous processing of the whole set of TNB1 observations, with the purpose of calculating the precipitable water variation over the period of 1998 to 2010. We implement up-to-date modeling of the phase observable to reduce the known systematic errors potentially affecting the precipitable water values.

The computation of the precipitable water requires the surface pressure and temperature records at the tracking site. When these observations are lacking, the information can be retrieved from global models (see Section 2). We use both global grid model values and accurate local observations to evaluate the differences between these two approaches. Thus, we test whether it is possible to compute the precipitable water from GPS data where no co-located surface atmospheric parameters are available; i.e., from the three additional semi-permanent GPS sites in Northern Victoria Land and from the episodic VLNDEF GPS campaigns (Figure 2). The GPS analysis strategy, and its models, parameterization and results are discussed in detail in Section 3.1.

For the purpose of validating/ comparing our GPS data with independent precipitable water estimates, we analyzed a set of 177 radiosoundings performed at MZS during the 2003/2004 Austral summer (from October 22, 2003, to February 5, 2004), using RS80-A Vaisala radiosondes only. Radiosoundings were performed relatively regularly during the MZS opening season, and they cover approximately three months every summer. No information on the water vapor content from in-situ measurements is available for the rest of the year. Consequently, the TNB1 data are the only means to locally retrieve a continuous time series of precipitable water.

Section 2 revisits the fundamental equations that relate the tropospheric composition to the satellite range delay. In Section 3, the dataset and the analysis strategies are described. In particular, Section 3.1 focuses on the GPS data analysis, while Section 3.2 concentrates on the radiosounding observations. It is well known that radiosounding measurements of pressure, 


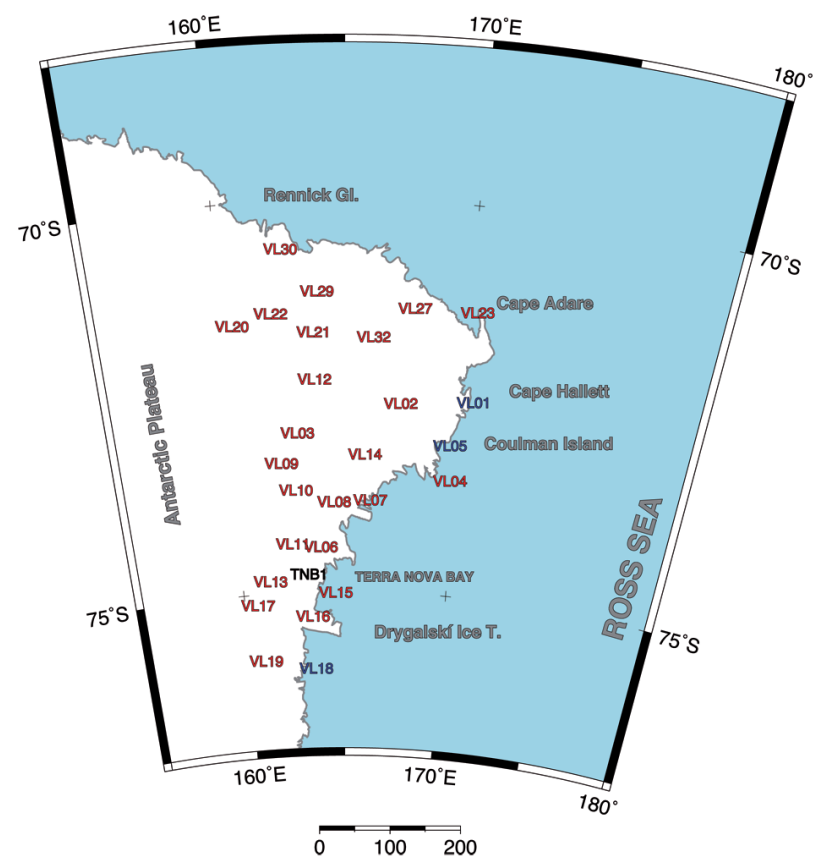

Figure 2. Map of the location of TNB1 and the VLNDEF network sites. VL01, VL05 and VL18 (blue) are semi-permanent GPS stations. The scale of the distances shown under the map is in $\mathrm{km}$.

temperature, and relative humidity are affected by numerous lag errors and dry bias. In particular, the sensors mounted on the RS80-A Vaisala radiosondes are affected by a variety of errors, the correction procedures for which have been carefully determined over the past two decades, through various studies and tests [Luers and Eskridge 1995, Miloshevich et al. 2001, 2004, 2006, Wang et al. 2002, Turner et al. 2003, Cady-Pereira et al. 2008]. Using these correction algorithms adapted to the harsh meteorological conditions that occur in Antarctica, we analyzed the above radiosonde measurements to reduce the most significant instrumental errors and dry bias of the Thermocap and Humicap sensors (see Section 3.2).

The precipitable water values obtained with GPS and radiosoundings are compared in Section 4.

\section{Modeling the tropospheric delay of the GPS signal}

According to, e.g., Hopfield [1978], the delay (or excess path) experienced by the GPS signals during propagation through the atmosphere can be expressed as:

$$
T D=\int_{\text {path }} n(s) d s-\rho
$$

where $n$ is the index of refraction of air, and $\rho$ is the slant range. If the signal path bending is small, the integral in Equation (1) can be evaluated along the geometric path $\rho$ [Bevis et al. 1992], thus obtaining:

$$
T D=\int(n(\rho)-1) d \rho
$$

or using the refractivity $N=10^{6}(n-1)$ :

$$
\mathrm{TD}=10^{-6} \int N(\rho) \mathrm{d} \rho .
$$

where $N$ can be divided conveniently into two parts [see e.g. Hoffman-Wellenhof et al. 2001]: $N=N_{\text {hyd }}+N_{\text {wet }}$, where $N_{\text {hyd }}$ is related to the atoms and molecules in the atmosphere without permanent dipole moments, which is also referred to as the dry refractivity, and $N_{\text {wet }}$ is related to the atmospheric water vapor, which is also referred to as the wet refractivity. It is therefore possible to express Equation (3) in the following form:

$$
T D=10^{-6}\left(\int N_{\text {hyd }}(\rho) d \rho+\int N_{\text {wet }}(\rho) d \rho\right)
$$

i.e., using the two terms related to the hydrostatic and wet refractivities. On this assumption, $T D$ is given by the sum of two integrals: the first provides the hydrostatic delay $(H D)$, and the second yields the wet delay (WD).

The total delay, as $T D=H D+W D$, is computed along the signal path, and it depends on the elevation $\alpha$ of the GPS satellites. At low satellite elevations, the signal goes through larger amounts of the atmosphere, and hence the delay is longer.

In practice, in the analysis of GPS observations (and for other geodetic radio-techniques), the zenith hydrostatic delay (ZHD) can be calculated a priori using a model [Davis et al. 1985]. The zenith total delay $Z T D=Z H D+Z W D$ is estimated in the GPS data analysis. The zenith wet delay $(Z W D)$ is obtained by subtracting the a-priori ZHD from the estimated ZTD. The TD can be expressed at any elevation as a function of the hydrostatic and wet delays along the zenith direction as:

$$
T D(\alpha)=m_{\text {hyd }}(\alpha) \cdot Z H D+m_{\text {wet }}(\alpha) \cdot Z W D .
$$

The mapping functions, $m_{\text {hyd }}(\alpha)$ and $m_{\text {wet }}(\alpha)$, have the very important role of relating the delays along the local vertical to the actual elevation of the satellite. Inaccurate mapping functions do not only impact on the GPS-derived water vapor content, but they also bias the station height estimates, with effects that can be as large as $1 \mathrm{~cm}$, and which are especially evident in Antarctica [Boehm et al. 2006a].

In the GPS data analysis, the partial derivative used to relate the ZTD parameters to the observed phase, $\partial Z T D / \partial \phi$, is usually the wet mapping function $m_{\text {wet }}(\alpha)$ [Tregoning and Herring 2006]. This means that corrections to $Z H D$, if required, are estimated as part of the corrections to $Z W D$. Therefore, when the aim is to determine accurate values of $Z W D$ (and precipitable water), it is mandatory to compute the a-priori $Z H D$ with the utmost level of accuracy. The ZHD can be computed using the formula [Saastamoinen 1973]: 


$$
Z H D=\frac{0.002277 \cdot p}{1-0.00266 \cos (2 \varphi)-0.0000028 h_{s}},
$$

where $p$ is the surface pressure at the site (expressed in $\mathrm{hPa}), \varphi$ is the site latitude, and $h_{s}$ is the geoidal height of the site (in m). It is evident from Equation (6) that once the actual position of the tracking site (latitude and height) is provided, the surface pressure determines the values of ZHD. Tregoning and Herring [2006] discussed the impact of using a standard reference pressure at sea level (corrected for station height) on the ZHD computation. They compared this latter standard approach (which has been widely adopted in GPS data analysis in cases where no local surface pressure records are available) with the results obtained using (i) grid values of surface pressure $p$ extracted from a global pressure and temperature model [Boehm et al. 2007], and (ii) real surface records. To do so, they evaluated the extent of the bias introduced by the former standard method on the ZTD and station heights, showing that when real surface parameters are missing, the ZHD grid values have to be used.

The ZWD can be obtained from the ZTD estimate by subtracting the $Z H D$ computed from Equation 6 :

$$
Z W D=Z T D-Z H D
$$

The final accomplishment of the precipitable water $(P W)$ retrieval is to transform the ZWD in precipitable water [Bevis et al. 1994]:

$$
P W=\Pi \cdot Z W D
$$

The dimensionless factor $\Pi$ is given by:

$$
\Pi=\frac{10^{6}}{\rho R_{v}\left[\left(k_{1} / T_{m}\right)+k_{2}^{\prime}\right]},
$$

where $\rho$ is the density of liquid water, $R_{v}$ is the specific gas constant for water vapor, $k_{1}, k_{2}^{\prime}=k_{2}-m k_{1}$ and $k_{2}$ are physical constants contained in the formula for refractivity $N$ [Smith and Weintraub 1953], and $m=$ $M_{w} / M_{a}$ is the ratio between the molar masses of water vapor and dry air. $T_{m}$ is a weighted mean temperature of the atmosphere, and according to Bevis et al. [1992], it can be computed locally using radiosounding measurements (see Section 3.1).

To summarize, when modeling the GPS phase observable, the roles of the mapping functions (Equation 5) and of the a-priori ZHD calculation (Equation 6) have been shown to be crucial to obtain accurate GPS estimates.

In the present study, we follow the specific recommendations for troposphere modeling that are contained in the International Earth Rotation and Reference Systems Service (IERS) Conventions [2010]. In particular, in the GPS data analysis, we used the Vienna Mapping Function (VMF1) for both the dry and wet components [Boehm et al. 2006b]. We also used the a-priori $Z H D$ values provided by the Technical University of Vienna, over a grid $\left(2.5^{\circ} \times 2.0^{\circ}\right)$ with ellipsoidal heights of an orographic surface, as available on the VMF1 webpage (http:/ / ggosatm.hg.tuwien.ac.at/DELAY/). The ZHD at the tracking site were computed with a bilinear interpolation of the ZHD given at the four nearest nodes of the grid. For each interpolated ZHD, the 'interpolated' pressure $p_{i}$ was computed from Equation (6). The height difference between the interpolated point and the tracking site was used to transform the pressure $p_{i}$ into the corresponding pressure $p_{s}$ at the tracking site height, according to the following equation:

$$
\begin{aligned}
& p_{s}=p_{i}+1013.25 \cdot \\
& \cdot\left[\left(1-0.0000226 \cdot h_{s}\right)^{5.225}-\left(1-0.0000226 \cdot h_{i}\right)^{5.225}\right] .
\end{aligned}
$$

The pressure $p_{s}$ was again used in Equation (6) to re-compute the $Z H D$ at the actual tracking-site height. It should be noted that at the moment there are no recommendations on the method to be adopted to perform such interpolations; we followed the approach adopted in Kouba [2008]. In addition to these grid-derived ZHD values, we used the $Z H D$ computed with the real surface pressure recorded at $\mathrm{MZS}$, to determine the differences between the two ZHD time series and to assess their effects on the GPS-derived precipitable water estimates.

\section{Data processing}

We analyzed the whole set of GPS observations performed at MZS by the permanent station TNB1 up to November 2010, to produce consistent and accurate time series of precipitable water. In addition, to validate our GPS precipitable water analysis strategy, and to compare our results with those derived by a totally independent measuring technique, we analyzed 177 radiosounding measurements recorded at MZS during the Austral summer of 2003 to 2004. To perform reliable comparisons, both datasets were processed while paying particular attention to the reduction in known systematic errors. The analysis strategies are described in the following Sections, 3.1 and 3.2.

\subsection{GPS analysis strategy}

We ran a modified version of the Bernese V.5.0 software (where VMF1 is implemented) in a double-differenced approach. A first run was performed to estimate the positions of more than 60 International Global Navigation Satellite System (GNSS) Service (IGS) stations and TNB1 in a global and consistent reference frame (Figure 3). To do so, we used the most re- 


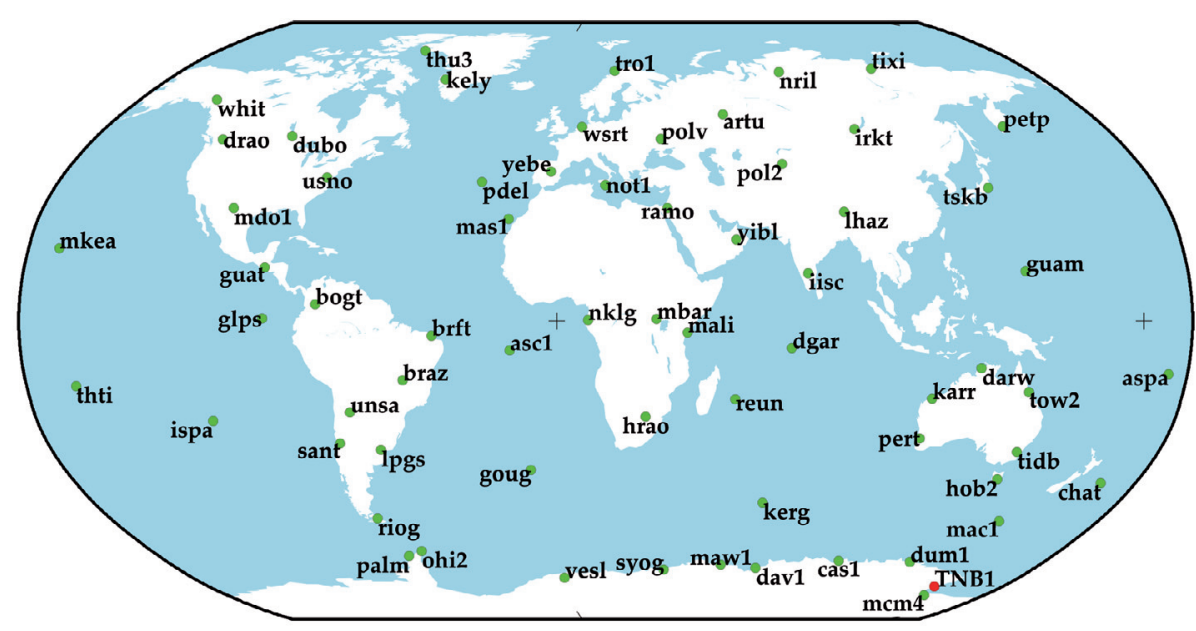

Figure 3. Map showing the distribution of the GPS stations from where the data were used in the analysis described in Section 3.1.

\begin{tabular}{ll}
\hline $\begin{array}{l}\text { Station coordinates/Sea surface heights } \\
\text { Solid Earth tide }\end{array}$ & $\begin{array}{l}\text { IERS Conventions } 2003 \\
\text { Cermanent tide }\end{array}$ \\
$\begin{array}{l}\text { Conventional tide-free system; IERS Conventions } 2003 \\
\text { UTCSR Ocean Tide Model from Schwiderski and Interpolation/ Ex- } \\
\text { trapolation }\end{array}$ \\
$\begin{array}{l}\text { Lides } \\
\text { Pole tides }\end{array}$ & $\begin{array}{l}\text { FES2004 trend for mean pole offsets: IERS Conventions } 2003 \\
\text { of the Earth due to the ocean tides }{ }^{b}\end{array}$ \\
Ocean loading & Not applied
\end{tabular}

Earth Orientation Parameters

A-priori information

IGS weekly ERP files (X-pole. Y-Pole, UT1-UTC) used with IGS precise orbits IG1 ${ }^{c}$

Subdaily EOP model

IERS2000

Nutation

IAU2000

\section{Troposphere modeling}

Hydrostatic delay

Mapping function for hydrostatic delay

Wet delay

Gradients

\section{Computed from 6-h ECMWF grids ${ }^{\mathrm{d}}$}

Hydrostatic VMF1 [Boehm et al. 2006b]

Zero a-priori model

Zero a-priori values, 24-h parameter estimated

\section{Technique-specific models}

Phase center model

Radome calibrations

Antenna height

Horizontal offsets

A-priori radiation pressure

\author{
igs08_1685.atx ${ }^{\mathrm{e}}$ [Schmid 2012] \\ igs08_1685.atx \\ igs.snx + IGSSTATION ${ }^{\mathrm{f}}$ \\ Applied \\ [Springer 2000]
}

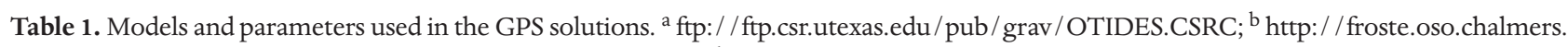
se/loading/; ${ }^{\mathrm{c} t \mathrm{tp}}$ // / cddis.gsfc.nasa.gov/gps/products/repro1; ${ }^{\mathrm{d}}$ http://ggosatm.hg.tuwien.ac.at/DELAY/; ${ }^{\mathrm{ftp}}$ ://igscb.jpl.nasa.gov/igscb/ station/general/; ${ }^{\mathrm{f} f t p}$ / / igscb.jpl.nasa.gov/igscb/station/log/.

cent IGS08 products: orbits, absolute phase center variation files, a-priori coordinates.

We embarked upon this time-consuming approach to estimate an accurate and consistent series of positions for TNB1, as these are fundamental in the estimation of the precipitable water (see Section 1). A detailed description of the parameterization of the phase observable is shown in Table 1, where all of the models and parameters are listed.

The software was run a second time, with the positions of the stations of the global network (Figure 3) estimated in the first run tightly constrained. We used 


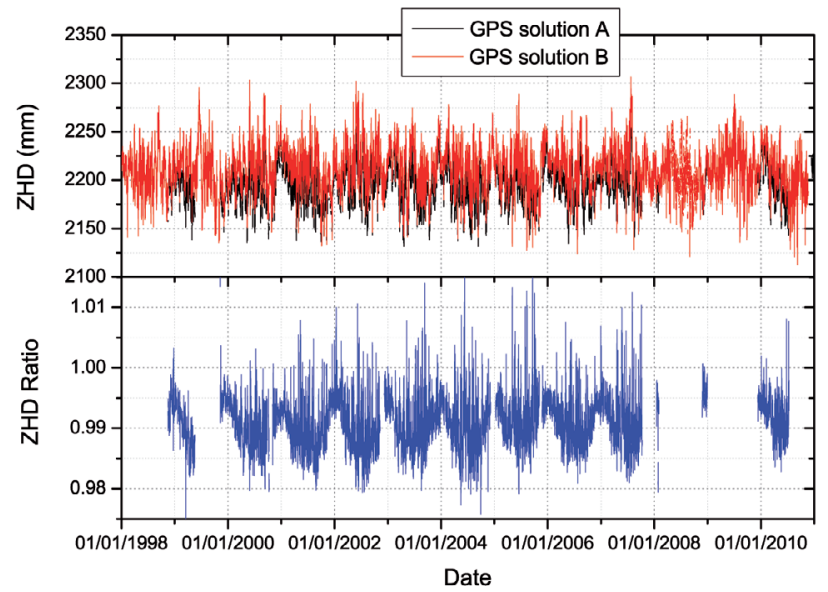

Figure 4. Top: Solution A (black), the ZHD time series for TNB1 obtained by interpolating the grid model values provided with the VMF1 mapping function coefficients (http:/ / ggosatm.hg.tuwien.ac. at/DELAY/). Solution B (red), the ZHD time series obtained with Equation (6) and the surface pressure $p$ data recorded at MZS by the automatic weather station Eneide. Bottom: Ratio of the ZHD times series (Solution A/Solution B; blue) shown in the top plot. The bias between the two series is represented by the discrepancy from unity. The seasonal variations of the bias are also evident.

the models shown in Table 1 again. In this way, we obtained a ZTD time series that was used to produce two time series of $Z W D$ (Equation 7). The first time series of $Z W D$ was computed by subtracting the $Z H D$ values that were obtained by the interpolation of the grid values of a global model derived from the ECMWF (see Section 2). Hereinafter, the grid $Z H D$ values are related to what will be identified as solution A. Similarly, the hourly ZHD derived from the real surface pressure values $p$ and computed according to Equation (6) were used to originate a second $Z W D$ time series using again Equation (7), and these correspond to solution B. The real surface pressure $p$ and the temperature data $T_{s}$ were recorded by Eneide, the automatic weather station at MZS. There is a height difference between TNB1 and Eneide of ca. $36 \mathrm{~m}$. According to the formula of Berg [1948], as presented in Boehm et al. [2007], this corresponds to a $4.3 \mathrm{hPa}$ difference, which was subtracted from the hourly pressure recorded at Eneide to obtain the equivalent pressure at the elevation of TNB1. It is worth mentioning that $\mathrm{a}+1 \mathrm{hPa}$ variation in Equation (6) impacts $Z H D$ values by ca. $+2.2 \mathrm{~mm}$ ! Hence, accurate records performed by calibrated atmospheric sensors and under the correct corrections, when necessary, are mandatory. The $Z H D$ time series that corresponds to solutions A and B are shown in Figure 4 (top).

The $Z H D$ values differ on average by $20.2 \mathrm{~mm}$ over the whole period, with a scatter of $8.5 \mathrm{~mm}$. Annual signals are clearly visible in the ZHD time series of Figure 4, although their amplitudes differ appreciably. Figure 4 (bottom) shows the ratio between the grid ZHD series (those used in solution A) and the corresponding ZHD computed with the surface pressure $p$ (solution B). The time series of the ratio highlights (i) the differences of $\triangle Z H D$ between the ZHD time series used in solutions $A$ and $B$ and reflected by the extent of discrepancy from unity, and (ii) the seasonal variations of $\triangle Z H D$. These latter derive from the smaller (larger) amplitude of the seasonal signal in the gridded $Z H D$ (the $p$-derived $Z H D$ ). The gridded $Z H D$ values in winter tend to diminish less (with respect to the summer values) than the corresponding $p$-derived $Z H D$ values. The seasonal dependency of the differences $\triangle Z H D$ between the two ZHD time series is shown in Figure 5, where the monthly means of $\triangle Z H D$ are plotted (over the period of 1998 to 2010). The $\triangle Z H D$ values clearly show monthly variations, and also show evident seasonal variations.

In December and January, during the Antarctic summer, the monthly differences are ca. $12 \mathrm{~mm}$, while they are ca. $23 \mathrm{~mm}$ from March to September. In terms of the a-priori pressure used in Equation (6), these discrepancies correspond to an error of ca. $5.5 \mathrm{hPa}$ and ca. $10.5 \mathrm{hPa}$, respectively. According to Tregoning and Herring [2006], the sensitivity of the station heights for every $1 \mathrm{hPa}$ error in the a-priori surface pressure is ca. $-0.19 \mathrm{~mm} / \mathrm{hPa}$, with larger effects at high latitudes. Thus, when using the grid ZHD, the height component of TNB1 might be in error of $-1 \mathrm{~mm}$ in summer and $-2 \mathrm{~mm}$ in winter. The effect on ZTD is smaller: it is ca. $+0.06 \mathrm{~mm} / \mathrm{hPa}$ and might impact on our ZTD estimate by no more than ca. $0.6 \mathrm{~mm}$ (in winter).

The $\triangle Z H D$ variations impact straightforwardly on the $Z W D$ (and $P W$ ), and their effects can be seen in Section 4 , where the GPS-derived precipitable water from solution $\mathrm{A}$ and $\mathrm{B}$ are compared to the radiosoundingderived precipitable water. In Section 4 we also show how the radiosounding results are crucial to assess the reliability of the ZHD time series, and their periodicity and amplitude.

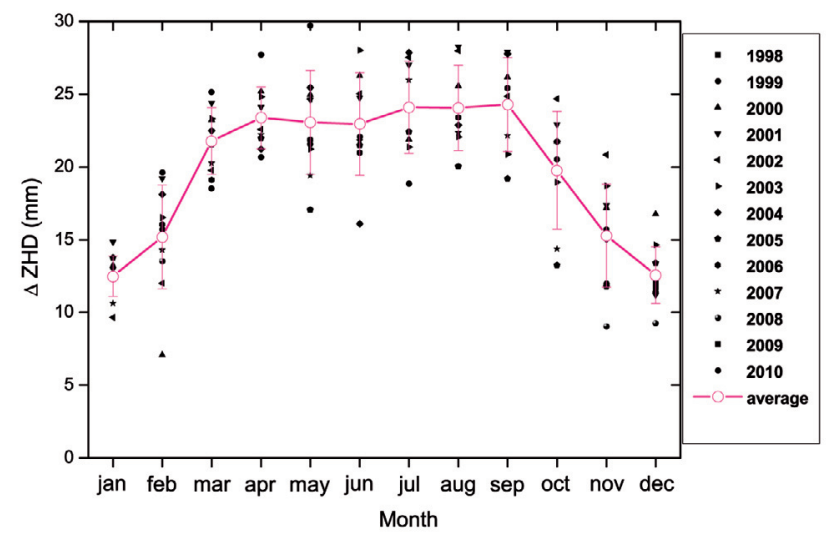

Figure 5. Monthly means of the differences, $\triangle Z H D$, between the $Z H D$ time series shown in Figure 4 (top). In particular, $\triangle Z H D=$ $Z H D_{p-\text { surf }}-Z H D_{\text {grid. }}$. The averages of the monthly means are shown with pink circles. 
As previously mentioned, to obtain the ZWD time series corresponding to solutions $A$ and $B$, we used Equation (7). The time series of ZTD derived from the second run of the Bernese software was combined with the two ZHD time series that were obtained from the grid model and from the real surface pressure records (Figure 4, top).

The ZWD series can be transformed into $P W$ according to Equation (8), once the mean temperature $T_{m}$ to be used in Equation (9) is known. Following Bevis et al. [1992], the $T_{m}$ values were derived locally from the analysis of 177 radiosounding measurements that were acquired during the Austral summer of 2003 to 2004 (see the following section). The linear relationship between the surface temperature $T_{s}$ (recorded at Eneide) and the mean temperature $T_{m}$ is shown in Figure 6.

This linear relationship was used to compute $T_{m}$ as a function of $T_{s}$ (recorded at Eneide) over the entire 1998 to 2010 period, and to compute the factor used to transform the ZWD into precipitable water. Figure 7 shows the precipitable water time series for solution $A$ (grid ZHD) and solution B ( $p$-derived ZHD).

Given the direct dependency of ZWD on ZHD through Equation (7), the differences between the precipitable water time series are a direct consequence of $Z H D$ and its seasonal dependence, as ZHD is directly transferred into $Z W D$ and scaled to PW through the factor $\Pi$.

The linear precipitable water trend computed over the whole period for solution $\mathrm{A}$ is $-0.055( \pm 0.001)$ $\mathrm{mm} / \mathrm{yr}$, and for solution $B$ it is $0.004( \pm 0.002) \mathrm{mm} / \mathrm{yr}$. These values are very near to zero and do not highlight any significant variation in the precipitable water over this period. Some values of the precipitable water determined during the Antarctic winter in solution B are negative, and these events are unrealistic and are not physically meaningful. They originate from some $p$-derived $Z H D$ values in winter that were larger than the corresponding ZTD estimates. These unrealistic events do not affect solution $\mathrm{A}$, the precipitable water time series of which is nonetheless affected by other problems, as shown in Section 4.

\subsection{Precipitable water estimation from radiosoundings}

The precipitable water $P W$ was calculated by integration of the absolute humidity $q(z)$ along the atmospheric vertical path up to $60 \mathrm{~km}$ in altitude. The daily vertical profiles of this moisture parameter were determined by analyzing the RS80-A radiosounding measurements of pressure $p(z)$, temperature $T(z)$, and relative humidity $R H(z)$ recorded at MZS on 177 days of the 2003/2004 Austral summer. The raw data provided by the Vaisala Barocap, Thermocap and Humicap-A sensors were examined using the correction algorithms proposed by Tomasi et al. [2004] to remove,

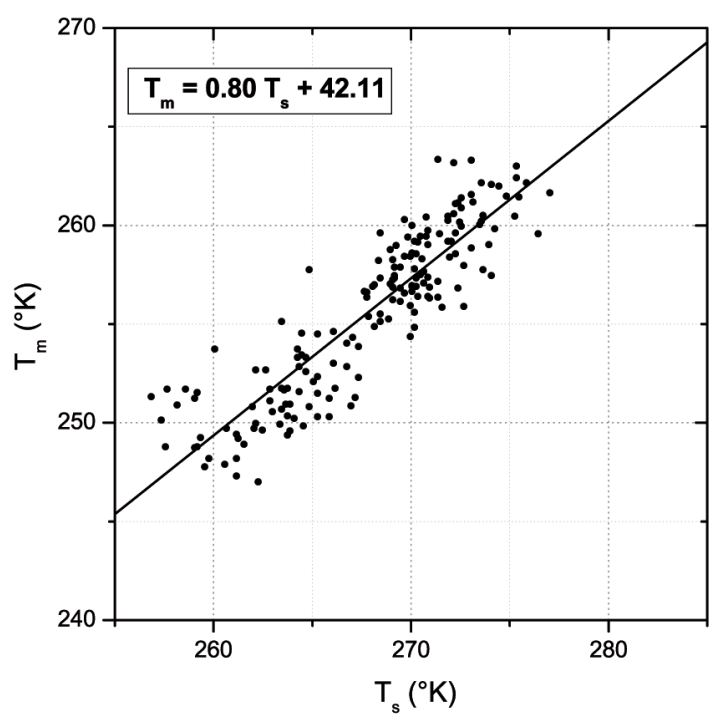

Figure 6. Linear relationship between the surface temperature $T_{s}$, recorded at Eneide, and the mean temperature $T_{m}$, computed from the radiosoundings. This is used over the entire time span to compute the $T_{m}$ from the $T_{s}$ and to compute the factor $\Pi$ to be used to transform $Z W D$ into $P W$.

or at least minimize, the instrumental errors, the timelag errors, and the dry bias of the three above-mentioned sensors. Therefore, a procedure that consisted of the following six steps was applied:

(1) No corrections were made to the raw RS80-A pressure data, because the instrumental errors of the Barocap sensor were assumed to be no greater than 0.5 $\mathrm{hPa}$ over the pressure range from 1060 to $3 \mathrm{hPa}$ at all altitudes, as the Barocap resolution was $1 \mathrm{hPa}$, as declared by the manufacturer.

(2) The errors affecting the RS80-A temperature data due to the combined heating effects caused by solar and infrared radiation absorption, heat conduction from the other radiosonde components, and heat exchange between the sensor and environment, were corrected using the Luers and Eskridge [1995] procedure.

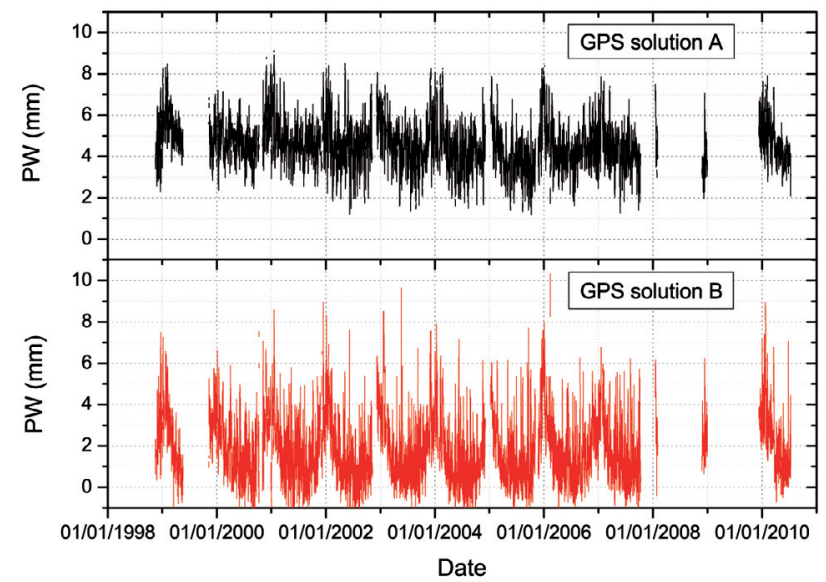

Figure 7. Precipitable water time series obtained from solution A (top) and B (bottom). The presence of negative values in the series of solution $B$ is discussed in the main text. 
(3) The temperature errors due to variations in the air density and ventilation speed were corrected using the algorithm defined by Tomasi et al. [2004].

(4) The errors of the relative humidity data were corrected using a variety of algorithms for the Humicap errors that were derived from the following different sources: (i) the time-lag errors were accounted for by assuming correct values of the Humicap time-constant, and a preliminary smoothing of the data was subsequently made, according to Miloshevich et al. [2004]; (ii) the RS80-A errors due to the so-called basic calibration model, temperature dependence, and sensor aging dry bias were substantially corrected using the algorithms of Wang et al. [2002]; and (iii) the chemical contamination dry bias was corrected using the algorithm defined by Wang et al. [2002] for RS80-A relative humidity data taken with 'young age' ( $<2$ years) sensors.

(5) Further relative humidity lag errors were removed by applying a second smoothing procedure, as recommended by Miloshevich et al. [2004].

(6) The solar heating dry bias that affected the daytime RS80-A Humicap data were considerably reduced by using the Cady-Pereira et al. [2008] algorithm, that was adapted to the Austral summer conditions of the Antarctic atmosphere by taking into account the dry bias evaluations of Turner et al. [2003] and Tomasi et al. [2006, 2012] in the Antarctic atmosphere.

Following these procedures, we obtained the corrected vertical profiles of $p(z), T(z)$ and $R H(z)$ for each radiosounding measurement, by determining the values of the three thermodynamic parameters at all of the relevant levels of each radiosounding, from the surface level up to $12 \mathrm{~km}$ altitude. Using these data, the saturation water vapor pressure $E(T)$ in the pure phase over a plane surface of pure liquid water was calculated at all of the levels in terms of the Murphy and Koop [2005] formula. For each value of $E(T)$ at level $z$, the water vapor partial pressure $e(z)$ was then calculated as the product of $E(T)$ using the corresponding value of $R H(z)$, to determine the water vapor mixing ratio $e(z) / p(z)$, for which the absolute humidity $q(z)$ was calculated in terms of the well-known equation of state for water vapor.

Each vertical profile of $q(z)$ determined following this procedure (up to a level of no more than $12 \mathrm{~km}$ ) was completed by assuming that $q(z)$ decreases exponentially with altitude, to reach the value of absolute humidity $q$ at level $z=15 \mathrm{~km}$ given by the corresponding monthly mean vertical profile of $q(z)$, chosen among the Michelson Interferometer for Passive Atmospheric Sounding (MIPAS) profiles determined by Tomasi et al. [2011a] at the $75^{\circ} \mathrm{S}$ latitude for the five months from October to February. These profiles were

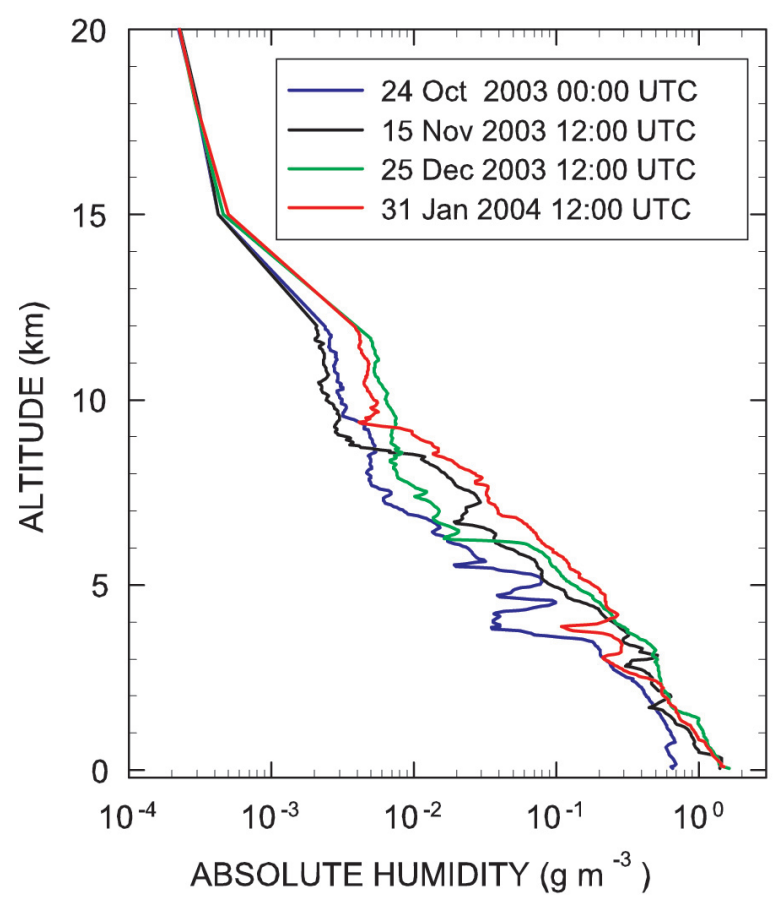

Figure 8. Four examples of vertical profiles of absolute humidity $q(z)$ (measured in $\mathrm{g} \mathrm{m}^{-3}$ ), as obtained from the radiosounding measurements performed at MZS (up to $12 \mathrm{~km}$ altitude) on four days of the 2003/2004 Austral summer, and completed with the monthly mean vertical profiles of $q(z)$ defined by Tomasi et al. [2011a] examining the MIPAS-ENVISAT observations recorded at levels $z \geq$ $15 \mathrm{~km}$ for the $75^{\circ} \mathrm{S}$ latitude, while the vertical profile of $q(z)$ over the $12<z \leq 15 \mathrm{~km}$ range was determined through a linear interpolation in altitude between the natural logarithms of $q(z)$.

calculated for the vertical profiles of $p(z), T(z)$ and water vapor mixing ratio $e(z) / p(z)$ determined over the $12 \mathrm{~km}$ to $60 \mathrm{~km}$ altitude range, from the MIPAS - Environmental Satellite (ENVISAT) limb-scanning measurements recorded at polar latitudes from July 2002 to April 2010 (Figure 8).

Finally, the monthly mean content of precipitable water in the upper atmosphere above the altitude of 60 $\mathrm{km}$ was totally neglected, since it is in all cases considerably smaller than the mean standard error made in the evaluation of the tropospheric content of precipitable water. Indeed, using the vertical profiles of pressure, temperature and water vapor mixing ratio defined by Anderson et al. [1986] over the $60 \mathrm{~km}$ to $120 \mathrm{~km}$ altitude range in the Subarctic Atmosphere models, the precipitable water was evaluated to be around $10^{-6} \mathrm{~mm}$, compared with the values of tropospheric precipitable water obtained from the radiosounding data collected at the MZS station, which mainly range between $2 \mathrm{~mm}$ and $8 \mathrm{~mm}$ over the period from October to February, with an average standard error of $\pm 0.4 \mathrm{~mm}$. Thus, considering the accuracy of the RS-80A radiosonde sensors and the precision of the overall correction procedure described above, it can be realistically assumed that the present evaluations of precipitable water obtained from the radiosounding measurements are, on average, af- 


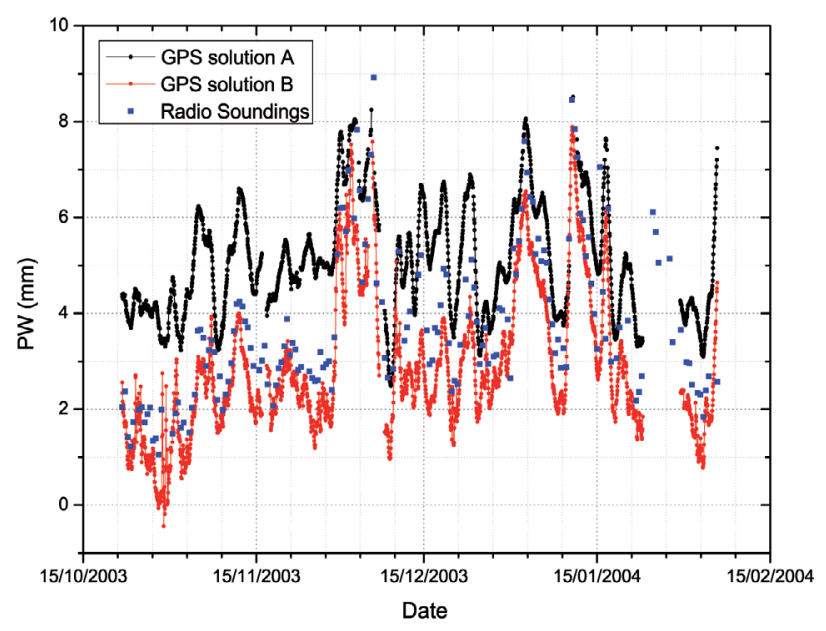

Figure 9. Hourly precipitable water time series derived from GPS solution A (black) and solution B (red). Blue squares, the precipitable water determined every $12 \mathrm{~h}$ by the radiosounding measurements.

fected by uncertainties not exceeding $10 \%$, as shown by Tomasi et al. [2011b].

\section{Intertechnique comparison}

The precipitable water time series derived by the radiosounding measurements have a crucial role in the assessment of the reliability of the GPS-derived precipitable water time series. As they are derived through a totally independent technique, the radiosounding results are useful to reveal and characterize possible bias. In particular, our solutions A and B show remarkable differences in the precipitable water content and seasonal variations. Figure 9 compares the hourly GPS-derived precipitable water with the 177 radiosoundingderived precipitable water values determined from October 2003 to February 2004.

Over this period, the GPS solution B agrees better with the radiosounding precipitable water time series. During the last 10 days of November and for the first days of December, the precipitable water content underwent a sudden, evident increase. The GPS solution $\mathrm{B}$ and the radiosoundings behave similarly, with the same increase and maintaining almost the same bias throughout the whole period (see also Figure 10). Over the same period, the precipitable water determined by GPS solution A did not vary as sharply as the other two solutions. As a consequence, during this particular period, the discrepancies with the other precipitable water time series decrease. To compare the GPS and radiosounding precipitable water time series, we computed the ratio between the corresponding precipitable water values (Figure 10).

Again, the plot of the ratios helps in the visualizing of the extent of the bias between the time series and the presence of any time-dependent effects. A dry bias affects the precipitable water derived from solution $\mathrm{B}$,

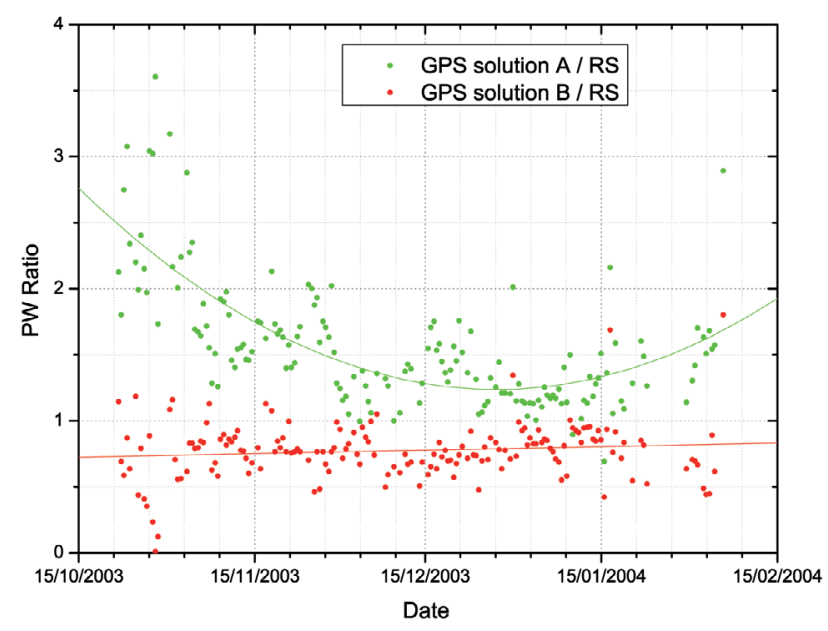

Figure 10. Precipitable water ratios between GPS solution A and the precipitable water derived by the radiosoundings (green), and the precipitable water from solution B and the radiosoundings (red). Solid lines, second-order (green) and first-order (red) interpolating functions.

the values of which are, on average, $77 \%( \pm 21 \%)$ of the corresponding radiosounding values of the precipitable water. As for the precipitable water of solution A, its values are $1.56( \pm 0.48)$-fold greater than the corresponding radiosounding values of the precipitable water, thus showing a remarkable wet bias over this period. The variations in the ratios over this period also require deeper consideration. Those computed from solution $\mathrm{B}$ and radiosoundings are relatively well interpolated by a linear function parallel to the axis of the abscissa (Figure 10, red line). This highlights that the bias of the two series is not time dependent, and both analysis (i.e., techniques) steadily follow the time variations of the precipitable water in a similar manner. Conversely, the ratios computed from solution A and radiosoundings show an evident dependency on time, to an extent that the values appear to be better interpolated by a second-order function (Figure 10, green line). The magnitude and variation in time of the ratios show that solution A not only overestimates the content of precipitable water, but does it more so in the colder months. This is a direct consequence of the actual $Z H D$ values interpolated from the grid model, the behavior of which with respect to the $p$-derived ZHD is shown in Figure 5. Specifically, as well as a seasonal dependency, the interpolated $Z H D$ values clearly underestimate the contribution of the hydrostatic component to the total delay. This might be related to the orography of the Baia Terra Nova coastal area and the way the grid $Z H D$ time series is transformed into the ZHD at the TNB1 height. Indeed, due to the steep topographical surface in the area, the heights of the four nearest nodes can be as different as $1.8 \mathrm{~km}$. The height of the interpolated point at the latitude and longitude of TNB1 is approximately $1.0 \mathrm{~km}$, and thus it differs considerably from the height of TNB1 itself (ca. $72 \mathrm{~m}$ ). 
A pressure correction is performed with Equation (10), to take into account the height difference and to transform the interpolated $Z H D$ into the corresponding value at the correct TNB1 height, as shown in Kouba [2008]. The procedure used might be inaccurate for such large height differences; other methods to transform the interpolated grid values to the tracking site height should be tested [e.g., Steigenberger et al. 2009a]. The seasonal effect might also be local and sitedependent, or might affect high latitude sites like those in Antarctica.

To distinguish between local and regional effects, further investigations are needed at other Antarctic sites, where permanent GPS observations, records of $p$ and $T_{s}$, and possibly all-year-round radiosounding measurements have been performed.

\section{Conclusions}

State of the art modeling, thorough knowledge of systematic errors, and optimized data analysis strategies are all required to overcome bias and to achieve accurate estimates of the parameters. We processed the continuous GPS observations acquired by a global network of more than 60 IGS stations for over a decade to produce a homogeneous precipitable water time series at MZS, Antarctica. Two different strategies were adopted for this purpose: one (solution A) was based on the use of grid ZHD model values and on their bilinear interpolation, to compute the $Z H D$ at the latitude and longitude of TNB1. To accommodate for the height discrepancy between the interpolated point and the tracking site height, the pressure was corrected according to Equation (10). From the new pressure values, the solution A ZHD time series was computed. The other strategy (solution B) was based on the use of hourly surface pressure values recorded at Eneide over the whole period. The two procedures originated rather different precipitable water time series: the precipitable water estimates derived from the grid values of ZHD are larger. Interestingly, the comparison of the precipitable water time series also highlighted a seasonal dependence bias. The monthly differences in the precipitable water vary between a minimum of ca. $1.8 \mathrm{~mm}$ in December and January (Austral summer), to a maximum of ca. $3.3 \mathrm{~mm}$ from March to September (with standard deviations ranging from $0.2 \mathrm{~mm}$ to $0.5 \mathrm{~mm}$ ). The variations in the monthly differences in precipitable water are related to the differences in the two ZHD time series (see Figure 5). In particular, since the computation of the hydrostatic delay at zenith is based on Equation (6), the differences most likely originate from the pressure values used as input, which (according to the $\triangle Z H D$ ) can vary between ca. $5.5 \mathrm{hPa}$ (sum- mer) and ca. $10.5 \mathrm{hPa}$ (winter).

In the present analysis, to compare the results with an independent and traditional measuring technique and to possibly assess the reliability of the two GPS solutions, the estimates of precipitable water derived from the radiosounding measurements were used. The radiosounding data were also processed by adopting a procedure optimized for systematic error reduction. The radiosounding results appear to be particularly important as they serve as a stable benchmark for assessing the extent of the bias of each GPS-derived precipitable water solution. For solution A, we obtained a larger, season-dependent bias. The seasonal variation was not highlighted by the comparison of solution $\mathrm{B}$ with the precipitable water derived from the radiosounding data. Again, this is related to the a-priori pressure values in the grid ZHD.

Our data show that in the area of MZS, to obtain accurate precipitable water time series, a lack of accurate surface-pressure records at TNB1 cannot be substituted by the ZHD values interpolated from a grid model. However, no rules have been set on how the transformation from the interpolated ZHD to the tracking site height should be performed; we used a method based on Equation (10), but it might be inaccurate for large height differences. Alternative methods to derive the ZHD at the tracking site from the grid values should be tested. If successful, these methods would eventually allow the use of VLNDEF sites and the semipermanent stations in Northern Victoria Land to determine the atmospheric precipitable water when no surface pressure data are available.

Acknowledgements. The authors thank two anonymous reviewers for their constructive comments. This study was carried out in the framework of the Programma Nazionale di Ricerche in Antartide (PNRA) and financially supported by PNRA S.C.r.1.. The authors thank the Meteo-Climatological Observatory of PNRA for providing the radiosounding measurements, and particularly Dr. A. Pellegrini and Dr. P. Grigioni. Figures 2 and 3 were produced using the Generic Mapping Tools [Wessel and Smith 1998].

\section{References}

Anderson, G.P., S.A. Clough, F.X. Kneizys, J.H. Chetwynd and E.P. Shettle (1986). AFGL Atmospheric Constituent Profiles (0-120 km), Environ. Res. Pap., 954, Opt. Phys. Div., Air Force Geophys. Lab., Hanscom Air Force Base, Mass., 43 pp.

Bennitt, G.V., and A. Jupp (2012). Operational assimilation of GPS zenith total delay observations into the met office numerical weather prediction models, Mon. Wea. Rev., 140 (8), 2706-2719; doi:10.1175/M WR-D-11-00156.1.

Berg, H. (1948). Allgemeine Meteorologie, Dümmler's Verlag, Bonn.

Bevis, M., S. Businger, T.A. Herring, C. Rocken, R.A. 
Anthes and R.H. Ware (1992). GPS meteorology: remote sensing of atmospheric water vapour using the global positioning system, J. Geophys. Res., 97, 15787-15801; doi:10.1029/92JD01517.

Bevis, M., S. Businger, S. Chiswell, T.A. Herring, R.A. Anthes, C. Rocken and R.H. Ware (1994). GPS meteorology: mapping zenith wet delays onto precipitable water, J. Appl. Meteorol., 33, 379-386.

Boehm, J., A. Niell, P. Tregoning and H. Schuh (2006a). Global Mapping Function (GMF): a new empirical mapping function based on numerical weather model data, Geophys. Res. Lett., 33, L07304; doi:10. 1029/2005GL025546.

Boehm, J., B. Werl and S. Harald (2006b). Troposphere mapping functions for GPS and very long baseline interferometry from European Centre for MediumRange Weather Forecasts operational analysis data, J. Geophys. Res., 111, B02406; doi:10.1029/2005JB0 03629.

Boehm, J., R. Heinkelmann and H. Schuh (2007). Short Note: A global model of pressure and temperature for geodetic applications, J. Geodesy, 81, 679-683; doi:10.1007/s00190-007-0135-3.

Cady-Pereira, K.E., M.W. Shephard, D.D. Turner, E.J. Mlawer, S.A. Clough and T.J. Wagner (2008). Improved daytime column-integrated precipitable water from Vaisala radiosonde humidity sensors, J. Atmos. Oceanic Technol., 25, 873-883; doi:10.1175/ 2007JTECHA1027.1.

Capra, A., S. Gandolfi, F. Mancini, P. Sarti and L. Vittuari (2002). VLNDEF project: Geodetic contribution to geodynamics study of Victoria Land, Antarctica, In: M. Sideris (ed.), Gravity, Geoid and Geodynamics 2000, International Association of Geodesy Symposia (Jul 31-Aug 04, 2000, Banff, Canada), 123, 379385, ISSN 0939-9585, ISBN 3-540-42469-5.

Capra, A., S. Gandolfi, F. Mancini, M. Negusini, P. Sarti and L. Vittuari (2003). Terra Nova Bay GPS permanent station, Terra Antartica Reports, 9, 21-24.

Capra, A., F. Mancini and M. Negusini (2007). GPS as a geodetic tool for geodynamics in Northern Victoria Land, Antarctica, Antarct. Sci., 19, 107-114; doi:10. 1017/S0954102007000156.

Capra, A., M. Dubbini, A. Galeandro, L. Gusella, A. Zanutta, G. Casula, M. Negusini, L. Vittuari, P. Sarti, F. Mancini, S. Gandolfi, M. Montaguti and G. Bitelli (2008). VLNDEF Project for Geodetic Infrastructure Definition of Northern Victoria Land, Antarctica, In: A. Capra and R. Dietrich (eds.), Geodetic and Geophysical Observations in Antarctica, Springer Berlin/Heidelberg, 37-72; doi:10.1007/978-3-54074882-3_3, ISBN: 978-3-540-74881-6.

Davis, J.L., T.A. Herring, I.I. Shapiro, A.E.E. Rogers and
G. Elgered (1985). Geodesy by radio interferometry - effects of atmospheric modeling errors on estimates of baseline length, Radio Sci., 20, 1593-1607; doi:10.1029/RS020i006p01593.

Dubbini, M., P. Cianfarra, G. Casula, A. Capra and F. Salvini (2010). Active tectonics in northern Victoria Land (Antarctica) inferred from the integration of GPS data and geologic setting, J. Geophys. Res., 115, B12421; doi:10.1029/2009JB007123.

Hofmann-Wellenhof, B., H. Lichtenegger and J. Collins (2001). Global Positioning System, Theory and Practice, $5^{\text {th }}$ edition, Springer, Wien/NewYork, ISBN 3-211-83534-2, 382 pp.

Hopfield, H.S. (1978). Tropospheric correction of electromagnetic ranging signals to a satellite: a study of parameters, In: P. Richardus (ed.), Proceedings of International Symposium on Electromagnetic Distance Measurement and the Influence of Atmospheric Refraction (May 23-28, 1977, Wageningen, The Netherlands), Netherlands Geodetic Commission, 205-215.

IERS Conventions (2003). IERS Technical Note; 32, edited by D.D. McCarthy and G. Petit, Verlag des Bundesamts für Kartographie und Geodäsie, Frankfurt am Main, 127 pp., ISBN 3-89888-884-3.

IERS Conventions (2010). IERS Technical Note; 36, edited by P. Gérard and B. Luzum, Verlag des Bundesamts für Kartographie und Geodäsie, Frankfurt am Main, 179 pp., ISBN 3-89888-989-6.

Kouba, J. (2008). Implementation and testing of the gridded Vienna Mapping Function 1 (VMF1), J. Geodesy, 82, 193-205; doi:10.1007/s00190-007-0170-0.

Luers, J.K., and R.E. Eskridge (1995), Temperature corrections for the VIZ and Vaisala radiosondes, J. Appl. Meteorol., 34, 1241-1253.

Mancini, F., A. Capra, S. Gandolfi, P. Sarti and L. Vittuari (2004). VLNDEF (Victoria Land Network for DEFormation control) monumentation during GANOVEX VIII - ItaliAntartide XV: Survey and data processing, Terra Antartica, 11, 35-38.

Miloshevich, L.M., H. Vömel, A. Paukkunen, A.J. Heymsfield and S.J. Oltmans (2001). Characterization and correction of relative humidity measurements from Vaisala RS80-A radiosondes at cold temperatures, J. Atmos. Oceanic Technol., 18, 135-156.

Miloshevich, L.M., A. Paukkunen, H. Vömel and S.J. Oltmans (2004). Development and validation of a time-lag correction for Vaisala radiosonde humidity measurements, J. Atmos. Oceanic Technol., 21, 1305-1327; doi:10.1175/1520-0426(2004)021<1305: DAVOAT > 2.0.CO;2.

Miloshevich, L.M., H. Vömel, D.N. Whiteman, B.M. Lesht, F.J. Schmidlin and F. Russo (2006). Absolute 
accuracy of water vapor measurements from six operational radiosonde types launched during AWEX$\mathrm{G}$ and implications for AIRS validation, J. Geophys. Res., 111, D09S10; doi:10.1029/2005JD006083.

Monaghan, A.J., D.H. Bromwich and D.P. Schneider (2008). Twentieth century Antarctic air temperature and snowfall simulations by IPCC climate models, Geophys. Res. Lett., 35, L07502; doi:10.1029/2007 GL032630.

Murphy, D.M., and T. Koop (2005). Review of the vapour pressures of ice and supercooled water for atmospheric applications, Q. J. R. Meteorol. Soc., 131, 1539-1565; doi:10.1256/qj.04.94.

Negusini, M., F. Mancini, S. Gandolfi and A. Capra (2005). Terra Nova Bay GPS permanent station (Antarctica): data quality and first attempt in the evaluation of regional displacement, J. Geodyn., 39 (Joint Assembly of the EGS/AGU/EUG, Nice, France, April 06-11, 2003), 81-90; doi:10.1016/j.jog.2004.10.002,

Rothacher, M., D. Angermann, T. Artz, W. Bosch, H. Drewes, M. Gerstl, R. Kelm, D. König, R. König and B. Meisel (2011). GGOS-D: homogeneous reprocessing and rigorous combination of space geodetic observations, J. Geodesy, 85, 679-705; doi:10.1007/s0 0190-011-0475-x.

Saastamoinen, J. (1973). Contributions to the theory of atmospheric refraction, Bulletin Géodésique (19461975), 107, 13-34; doi:10.1007/BF02522083.

Schmid, R. (2012). IGS Antenna Working Group, In: M. Meindl, R. Dach and Y. Jean (eds.), IGS Technical Report 2011, 133-137; ftp:/ /igs.org/pub/resource/ pubs/2011_techreport.pdf.

Smith, E.K., and S. Weintraub (1953). The constants in the equation for atmospheric refractive index at radio frequencies, Proc. IRE, 41, 1035-1037.

Springer, T.A. (2000). Modeling and Validating Orbits and Clocks Using the Global Positioning System, Geod. Geophys. Arb. in der Schweiz, 60, Zürich, Switzerland.

Steigenberger, P., M. Rothacher, R. Dietrich, M. Fritsche, A. Rülke and S. Vey (2006). Reprocessing of a global GPS network, J. Geophys. Res., 111, B05402; doi:10. 1029/2005JB003747.

Steigenberger, P., V. Tesmer, M. Krügel, D. Thaller, R. Schmid, S. Vey and M. Rothacher (2007). Comparisons of homogeneously reprocessed GPS and VLBI long time-series of troposphere zenith delays and gradients. J. Geodesy, 81, 503-514; doi:10.1007/s001 90-006-0124-y.

Steigenberger, P., J. Boehm and V. Tesmer (2009a). Comparison of GMF/GPT with VMF1/ECMWF and implications for atmospheric loading, J. Geodesy, 83, 943-951; doi:10.1007/s00190-009-0311-8.
Steigenberger, P., M. Rothacher, M. Fritsche, A. Rülke and R. Dietrich (2009b). Quality of reprocessed GPS satellite orbits, J. Geodesy, 83, 241-248; doi:10.1007/ s00190-008-0228-7.

Tesmer, V., P. Steigenberger, M. Rothacher, J. Boehm and B. Meisel (2009). Annual deformation signals from homogeneously reprocessed VLBI and GPS height time series, J Geodesy, 83, 973-988; doi:10.100 7/ s00190-009-0316-3.

Thomas, I.D., M.A. King, P.J. Clarke and N.T. Penna (2011). Precipitable water vapor estimates from homogeneously reprocessed GPS data: an intertechnique comparison in Antarctica, J. Geophys. Res., 116, D04107; doi:10.1029/2010JD013889.

Tomasi, C., A. Cacciari, V. Vitale, A. Lupi, C. Lanconelli, A. Pellegrini and P. Grigioni (2004). Mean vertical profiles of temperature and absolute humidity from a twelve-year radiosounding data-set at Terra Nova Bay (Antarctica), Atmos. Res., 71, 139-169; doi:10.1016/j.atmosres.2004.03.009.

Tomasi, C., B. Petkov, E. Benedetti, V. Vitale, A. Pellegrini, G. Dargaud, L. De Silvestri, P. Grigioni, E. Fossat, W.L. Roth and L. Valenziano (2006). Characterization of the atmospheric temperature and moisture conditions above Dome C (Antarctica) during austral summer and fall months, J. Geophys. Res., 111, D20305; doi:10.1029/2005JD006976.

Tomasi, C., B. Petkov, B.M. Dinelli, E. Castelli, E. Arnone and E. Papandrea (2011a). Monthly mean vertical profiles of pressure, temperature and water vapour volume mixing ratio in the polar stratosphere and low mesosphere from a multi-year set of MIPAS-ENVISAT limb-scanning measurements, J. Atmos. Solar-Terr. Phys., 73, 2237-2271; doi:10.1016/ j.jastp.2011.06.018.

Tomasi, C., B. Petkov, E. Benedetti, L. Valenziano and V. Vitale (2011b). Analysis of a 4 year radiosonde data set at Dome $\mathrm{C}$ for characterizing temperature and moisture conditions of the Antarctic atmosphere, J. Geophys. Res., 116, D15304; doi:10.1029/2 011JD015803.

Tomasi, C., B.H. Petkov and E. Benedetti (2012). Annual cycles of pressure, temperature, absolute humidity and precipitable water from the radiosoundings performed at Dome C, Antarctica, over the 2005-2009 period, Antarct. Sci., 24, 637-658; doi:10. $1017 /$ S0954102012000405.

Tregoning, P., and Herring, T.A. (2006). Impact of $a$-priori zenith hydrostatic delay errors on GPS estimates of station heights and zenith total delays, Geophys. Res. Lett., 33, L23303; doi: 10.1029/2006GL027706. Turner, D.D., B.M. Lesht, S.A. Clough, J.C. Liljegren, H.E. Revercomb and D.C. Tobin (2003). Dry bias 
and variability in Vaisala RS80-H radiosondes: The ARM experience, J. Atmos. Oceanic Technol., 20, 117-132.

Vey, S., R. Dietrich, M. Fritsche, A. Rülke, P. Steigenberger and M. Rothacher (2009). On the homogeneity and interpretation of precipitable water time series derived from global GPS observations, J. Geophys. Res., 114, D10101; doi:10.1029/2008JD010415. Vonder Haar, T.H., J. Bytheway and J.M. Forsythe (2012). Weather and climate analyses using improved global water vapor observations, Geophys. Res. Lett., 39, L15802; doi:10.1029/2012GL052094.

Wang, J., H.L. Cole, D.J. Carlson, E.R. Miller, K. Beierle, A. Paukkunen and T.K. Laine (2002). Corrections of humidity measurement errors from the Vaisala RS80 radiosonde - Application to TOGA COARE data, J. Atmos. Oceanic Technol., 19, 981-1002.

Wang, J., L. Zhang, A. Dai, T. Van Hove and J. Van Baelen (2007). A near-global, 2-hourly data set of atmospheric precipitable water from ground-based GPS measurements, J. Geophys. Res., 112, D11107; doi:10.1029/2006JD007529.

Wessel, P., and W.H.F. Smith (1998). New, improved version of the Generic Mapping Tools released, Eos Trans. AGU, 79, 57

${ }^{\star}$ Corresponding author: Pierguido Sarti,

Istituto di Radioastronomia (IRA), Istituto Nazionale di Astrofisica (INAF), Bologna, Italy; email: p.sarti@ira.inaf.it. 